\title{
EFFECT OF WELDING PROCESSES ON MICROSTRUCTURE OF Ti6AI4V WELDMENTS
}

\author{
Bupesh Raja V.K. ${ }^{1}$, Palani Kumar K. ${ }^{2}$, Elangovan K. ${ }^{3}$, Manoharan N. ${ }^{4}$ \\ ${ }^{1}$ Research Scholar, Department of Mechanical and Production Engineering, Sathyabama University, Chennai, India \\ ${ }^{2,3,4}$ Sathyabama University, Chennai, India \\ Email: 'bupesh_r@rediffmail.com
}

\begin{abstract}
The titanium alloys are widely used in aerospace, highly corrosive environments and prosthetics. Among the titanium alloys, Ti6Al4V is used much, due to its high strength to weight ratio and its ability to easy fabrication. The Ti6Al4V has good weldability, but it is susceptible to hydrogen embrittlement. The welding technique used for fabricating the Ti6AI4V makes a significant effect in the microstructure of the weldments. The microstructural changes are significant, since it determines the properties, behaviour and reliability of the welded joints. This investigation was done to determine the changes in the microstructure of butt joints prepared from $3 \mathrm{~mm}$ rolled plates. The welding was done using Gas-Tungsten Arc Welding (GTAW) and Laser Beam Welding (LBW) processes. In both the processes argon with $99.9 \%$ purity was used for shielding, to avoid any contamination. In this investigation it was found that the Laser Beam Welding produced weldments with smaller heat affected zone and associated high hardness.
\end{abstract}

Key words: Ti-6AI-4V, GTAWF, GTAWA, LBW, Micro Hardness, Microstructure, Macrostructure

\section{INTRODUCTION}

TITANIUM is the seventh, abundant metal available in the earth crust [1]. Titanium and its alloys are applied in places where, corrosion-resistance like petrochemical plants and high strength to weight ratio, as required in the aerospace industry and in biocompatible prosthetics as in medical field. Among the various alloys of titanium, the Ti6AI4V is widely used in the industries [2]. Titanium is a allotropic metal existing in closed - packed hexagonal structure at room temperature, known as alpha phase and at $885{ }^{\circ} \mathrm{C}$ it transforms to a body - centered cubic structure, known as beta phase. The beta phase is stronger than the alpha phase, but brittle in nature [3]. Based on the allotropic phases titanium alloys are classified as alpha, beta and alpha - beta alloys. The Ti6Al4V is a alpha-beta alloy, comprising aluminium as the alpha stabilizer; which increases the tensile strength, creep strength and the elastic moduli; and vanadium as the beta isomorphous type of beta stabilizer; which increases the resistance to stress-corrosion cracking. Generally the gas tungsten arc welding- Autogenous (GTAWA) is used to weld titanium and its alloys [4-8]. The argon gas is used as shield the weld pool from contamination and to prevent hydrogen embrittlement [919]. Nowadays high-energy intense welding techniques like LASER beam welding are also used to implement critical applications [20-22]. Therefore in this investigation Ti6Al4V plate was welded by using the two techniques, viz, the gas tungsten arc welding (GTAW) and LASER beam welding (LBW) and associated microstructural changes are studied.

\section{EXPERIMENTAL PROCEDURE}

The $3 \mathrm{~mm}$ thick, cold rolled, annealed plates of Ti6AI4V, as perASTM B265, were cut into sizes ( 50 x $125 \mathrm{x}$ $3 \mathrm{~mm}$ ), along the rolling direction for fabricating the square buttjoint. Fig. 1.

The joints were fabricated autogenously and using filler wire of the same composition. Table. 1,2. The composition of the base metal and the weld metal was determined using a vacuum optical emission spectrometer (SPECTRO - LAB, Germany).

Table 1. Chemical Composition (wt \%) of the Base Metal

\begin{tabular}{|l|l|l|l|l|l|l|l|l|l|l|}
\hline Al & V & C & Si & Mn & $\mathrm{Cr}$ & $\mathrm{Ni}$ & $\mathrm{Cu}$ & $\mathrm{Fe}$ & $\mathrm{Sn}$ & $\mathrm{Ti}$ \\
\hline
\end{tabular} \begin{tabular}{|l|l|l|l|l|l|l|l|l|l|l|}
\hline 6.508 & 3.943 & 0.034 & 0.005 & 0.0048 & 0.014 & 0.0136 & 0.0050 & 0.183 & 0.028 & 89.253 \\
\hline
\end{tabular}

Table 2. Chemical Composition (Wt \%) of the Weld Metal in GTAWA

\begin{tabular}{|l|l|l|l|l|l|l|l|l|l|l|l|l|}
\hline Al & V & $\mathrm{C}$ & $\mathrm{Si}$ & $\mathrm{Mn}$ & $\mathrm{Cr}$ & $\mathrm{Ni}$ & $\mathrm{Cu}$ & $\mathrm{Fe}$ & $\mathrm{Sn}$ & $\mathrm{Zr}$ & $\mathrm{Mo}$ & $\mathrm{Ti}$ \\
\hline 5.964 & 3.908 & 0.030 & 0.010 & 0.0061 & 0.017 & 0.0117 & 0.1242 & 0.186 & 0.035 & 0.011 & 0.004 & 89.693 \\
\hline
\end{tabular}

The GTAWA was done manually, using Easy Weld SSR 400/600, 3 phase, $415 \mathrm{~V} \pm 10 \%, 50 \mathrm{~Hz}$ Ac equipment. The GTAWA was done with a root gap of $1.6 \mathrm{~mm}$. The LBW was done with no root gap, since any gap between the plates lets the laser beam to pass through without performing any welding. The GTAW was done with proper care to prevent any contamination, distortions and embrittlement, by using $99.9 \%$ pure argon with top and bottom purging and suitable clamping.

The frequency of the GTAW was kept constant as 6 $H Z$. The weld bead, quality of weld and full penetration was 
achieved by selecting suitable welding parameters. Table. 3,4 . shows process parameters used in this investigation.

Table 3. GTAWF Parameters

\begin{tabular}{|c|c|c|l|l|}
\hline & Current & Volt & $\begin{array}{l}\text { Feed } \\
\text { mm/minute }\end{array}$ & $\begin{array}{l}\text { Filler wire } \\
\text { Diameter }\end{array}$ \\
\hline $\begin{array}{l}\text { Root } \\
\text { run }\end{array}$ & $90 \mathrm{~A}$ & $12 \mathrm{~V}$ & 136 & $1.6 \mathrm{~mm}$ \\
\hline $\begin{array}{l}\text { Fill } \\
\text { up }\end{array}$ & $83 \mathrm{~A}$ & $11.9 \mathrm{~V}$ & 129 & $2.5 \mathrm{~mm}$ \\
\hline
\end{tabular}

Table 4. GTAWA Parameters

\begin{tabular}{|l|l|l|c|}
\hline & Current & Volt & Feedmm/minute \\
\hline Root run & $102 \mathrm{~A}$ & $17 \mathrm{~V}$ & 134 \\
\hline Fill up & $86 \mathrm{~A}$ & $16.2 \mathrm{~V}$ & 188 \\
\hline
\end{tabular}

In order to avoid porosity and to utilize the full length of the plate, starting and ending tab was used in GTAW as shown in Fig.1. [23]. In the GTAW, square butt welds were made using filler wire(GTAWF) and autogenously without filler wire (GTAWA), but in the LBW process only autogenous weld were made, in the automated LBW machine.

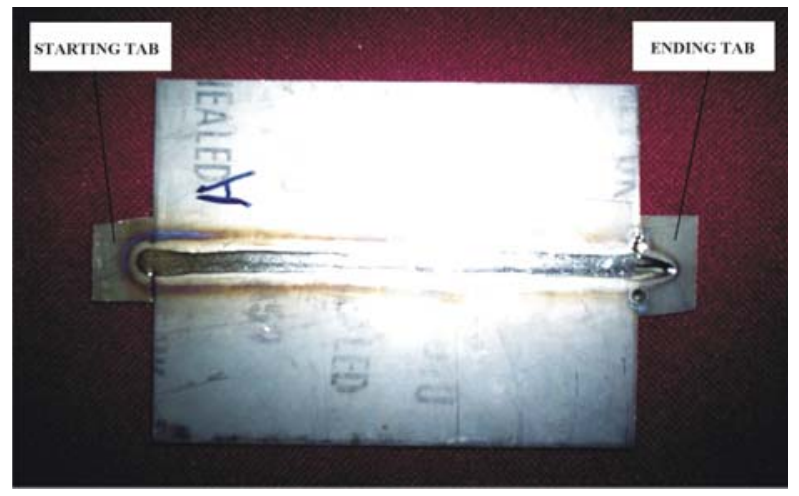

Fig. 1. Use Of Starting And End Tab In CCGTAW

The laser beam-welding machine used for this experiment was a transverse flow, Carbondioxide LASER. A transparent ZnSe lens with focal position of $20 \mathrm{~mm}$ and a laser beam of 30 to $32 \mathrm{~mm}$ diameter were used. The laser used was a conduction type of laser welding method used for low power heat requirements. [24-26]. The laser beam welding equipment was a computer numerically controlled system, to achieve control on the welding parameters.

The plates to be welded were placed inside an open top transparent chamber to provide foolproof shielding by flooding the chamber with argon of $99.9 \%$ purity. The joint was purged and the chamber was filled with argon to flush any atmospheric air inside the chamber. The shielding was achieved using a fixture to purge argon, from top and bottom of the titanium plates, in addition to the coaxial flow of argon coming along the direction of the laser beam.
Initially a tracking laser beam of $150 \mathrm{~W}, 5 \mathrm{~A}, 1.47 \mathrm{KV}$ was used to mark and check the alignment of the weld joint. The laser beam welding was conducted with suitable parameters to achieve full penetration without any defects as shown in Table. 5 .

Table 5. Laser Beam Welding Parameters.

\begin{tabular}{|l|l|l|l|}
\hline Current & Voltage & Power & $\begin{array}{l}\text { Feed } \\
\text { mm/minute }\end{array}$ \\
\hline $25 \mathrm{~A}$ & $2.12 \mathrm{KV}$ & $3.5 \mathrm{KW}$ & 56 \\
\hline
\end{tabular}

The macro structural examinations of the weldments were done using a stereomicroscope (METZER Stereo), with $10 \mathrm{X}$ magnification.

The metallographic specimens were taken in the transverse section and prepared as per standard metallographic procedure and etched with Krolls reagant (10 $\mathrm{ml} \mathrm{HF}, 30 \mathrm{ml} \mathrm{HNO} 3$ and $50 \mathrm{ml} \mathrm{H} 2 \mathrm{O}$, as per ASTM 187). The micro etching was done by immersing the specimen in the etchant for 3 to 10 seconds [27].

The microstructural examinations of the weldments were done using a optical microscope (METAVIS 1000). The metallographic specimens taken in the transverse section were prepared by polishing with several grades of emery papers and polished with lavigated alumina $(0.0013$ $\mu \mathrm{m}$ particle size) and final polishing was done using diamond polishing compound $(0.25 \mu \mathrm{m}$ particle size). The polished specimens were etched with Krolls reagant (1 to $3 \mathrm{ml} \mathrm{HF}, 2$ to $6 \mathrm{ml} \mathrm{HNO}_{3}$ and $100 \mathrm{ml} \mathrm{H}_{2} \mathrm{O}$, as perASTM 192). [28].

The microhardness examinations were carried out using "ILSON WOLPERT Micro Vickers Hardness Tester", with $0.5 \mathrm{~kg}$ load.

\section{RESULTS AND DISCUSSION}

\section{A. Macrostructural Investigation}

In the GTAW and LBW macrographs the fusion zone (FZ), heat affected zone (HAZ) and parent metal (PM) are distinctly visible. Fig. 2, 3, 4. The parent metal (PM) in GTAWA and GTAWF shows the direction of rolling parallel to the transverse direction; since the cold rolled Ti6Al4V plates were cut perpendicular to the rolling direction. The heat-affected zone (HAZ) is broad in GTAWF due to the high heat input. This causes significant grain growth above $\alpha / \beta$ transus temperature. The formation of $\alpha$-lamella from the prior $\beta$, is dependant on the cooling rate at $\beta$ transus temperature. The faster the rate of cooling, the finer the lamella formed during the phase transformation. 


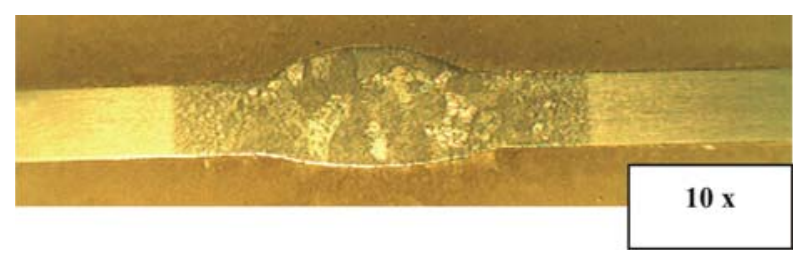

Fig. 2. Macrostructure of GTAWF-Transverse Direction

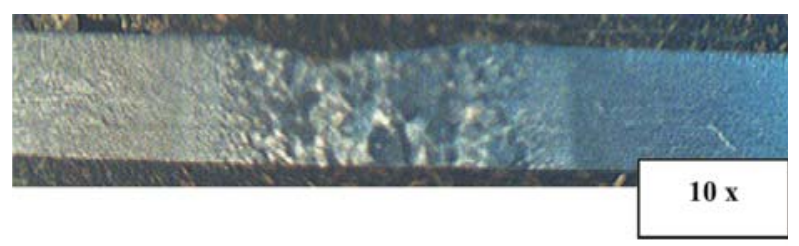

Fig. 3. Macrostructureof GTAWA -Transverse Direction

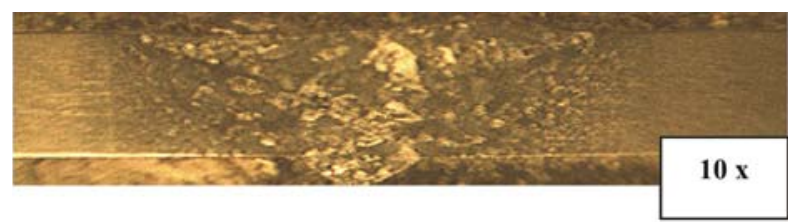

Fig. 4. Macrostructure of LBW-Transverse Direction

In the longitudinal section, GTAWA and GTAWF, vertically oriented columnar grains are observed. The multi pass welding with low energy input leads to the reduction of beta grain size and due to the successive epitaxial nucleation of beta grains with each layer results in the formation of vertically oriented columnar beta grains. Fig. 5, 6 .

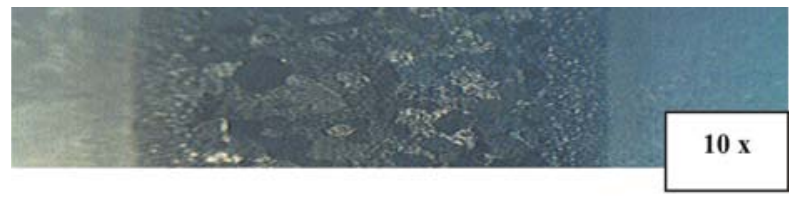

Fig. 5. Macrostructure of GTAWF- Longitudinal Direction

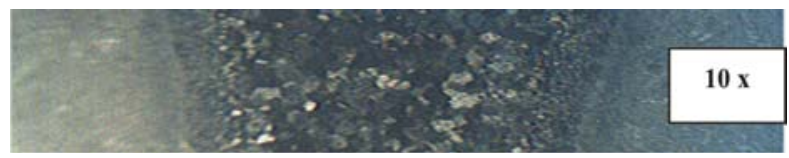

Fig. 6. Macrostructure of GTAWA-Longitudinal Direction

In the longitudinal section of the laser beam weldment, the grains in the fusion zone are coarse columnar grains which are nucleated or oriented epitaxially from the heat affected zone - fusion zone interface, grow towards the weld pool and parallel to the direction of the maximum temperature gradient. The longitudinal section of the LBW weldment, shows solidified and heat affected microstructure above á/â transus with little grain growth, due to short heating cycle. Fig. 7.

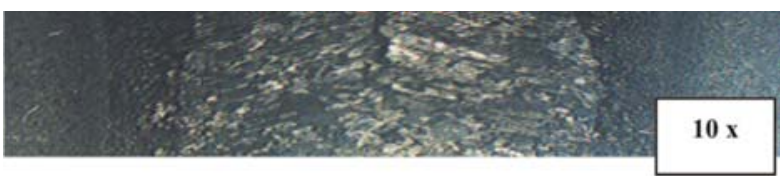

Fig. 7. Macrostructure of LBW-Longitudinal Direction

\section{B. Microstructural Investigation}

The Parent metal is a cold rolled, annealed plate. The longitudinal section shows the rolling direction. The structure consists of elongated á grains in a matrix of transformed â. Fig. 8. The transverse section of the parent metal shows elongated á grains in a matrix of intergranular â (gray). the grains are better resolved and the both alpha and beta grains are clearly seen. Fig. 9 .

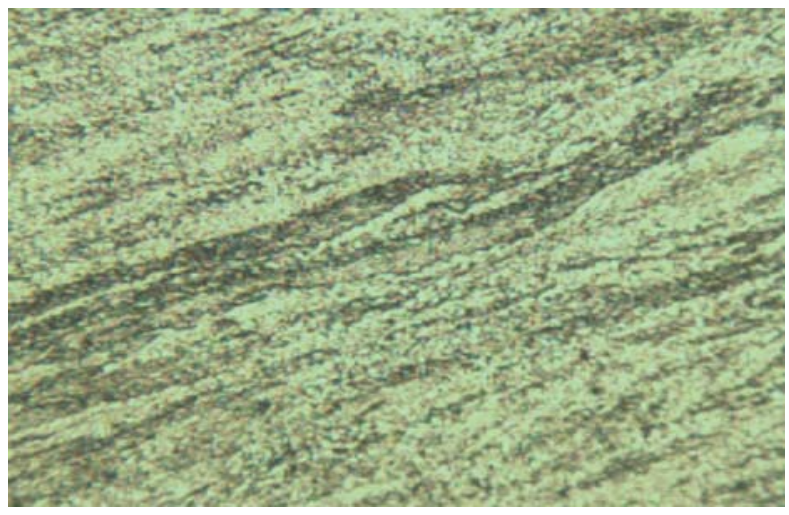

Fig. 8. Microstructure of

Parent metal-Longitudinal Section

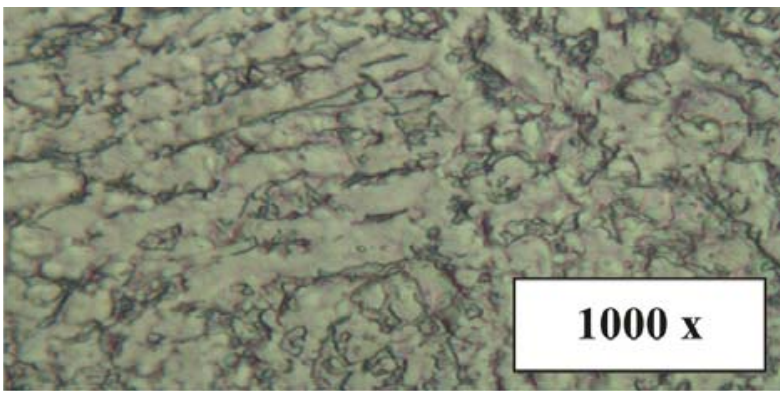

Fig. 9. Microstructure of Parent metal -Transverse Section

\section{Microhardness Investigation}

The microhardness values of the GTAWA and GTAWF weldments revealed a reduction in the hardness in some locations of the fusion zone and in most places at the heat affected zone and in the fusion zone the hardness value was equal to that of the parent metal.

The reason for the reduction in hardness was due to the formation of more a grains and less number of $\beta$ grains, caused by the heat dissipation made by consecutive layers of weld passes. This causes slow cooling and thus promoting growth of a grain formed 
during the annealing conditions that prevailed inside the weldment. This effect is similar to the preheating process, which increases the size of the heat-affected zone and reduces the rate of cooling of the weldment. The slow cooling or annealing process minimizes the martensite formation. On observing the microstructures it could be said that, a higher hardness value would indicate the presence of a hard microstructure and vice versa. In this investigation the martensite structures (dark) are of higher hardness and the alpha (light) has lower hardness. Fig.10, 11,12 . The optical microscopy is considered as not an exact method of studying the, $a$ and $\beta$ phases in Ti6AI4V, because of the non-uniform etching response of their phase. The severely etched locations could be considered as $\beta$ and the lightly etched locations could be considered as $\alpha$. The laser beam welded joints resulted in small aspect ratio and increased hardness due to the short period of exposure to the laser heat input and followed by rapid quenching. The microhardness increases from the parent metal to the fusion zone along the transverse direction. Fig.13.

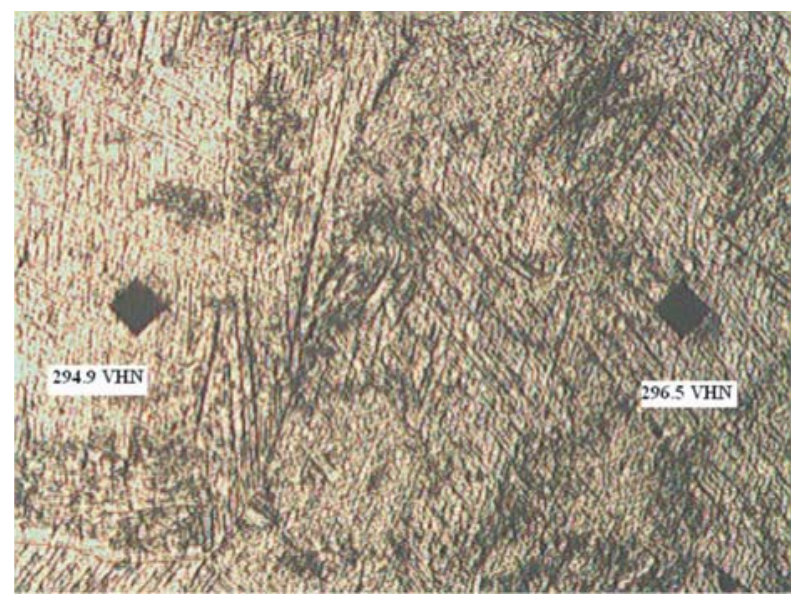

Fig.10. Microphotograph of GTAWF with Micro hardness Indentations.

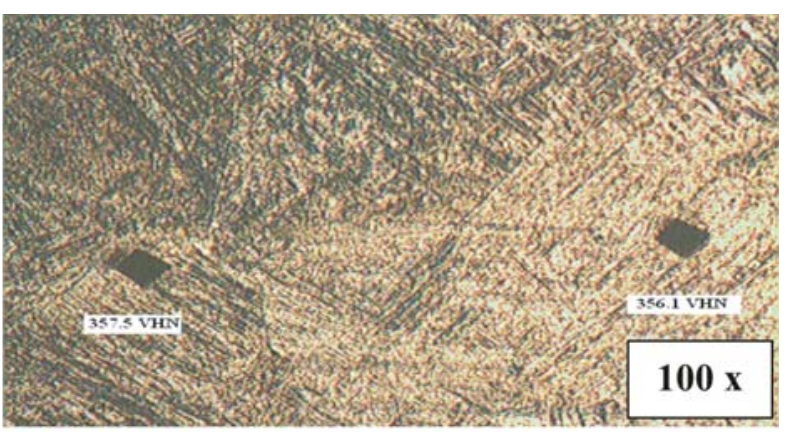

Fig. 11. Microphotograph of GTAW with Microhardness Indentations.

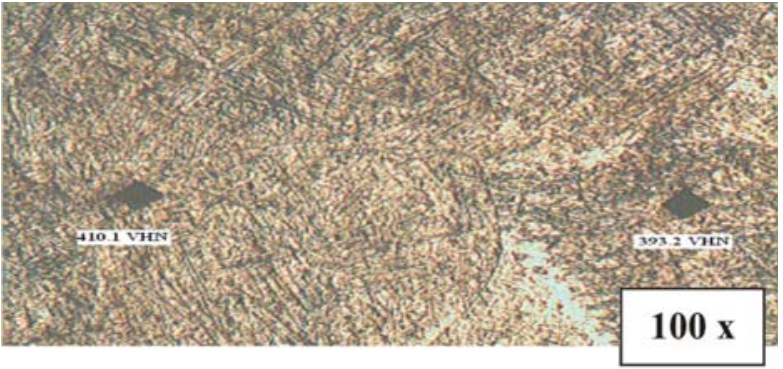

Fig. 12. Microphotograph of LBW with Microhardness Indentations.

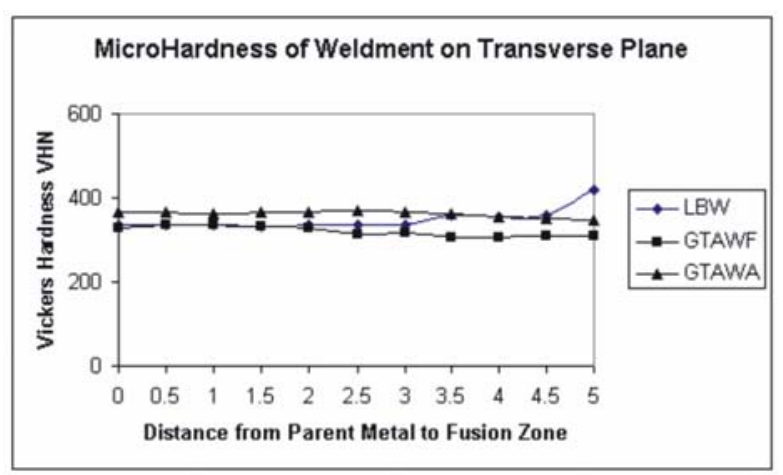

Fig. 13. Microhardness along transverse plane of GTAWF, GTAWA and LBW Ti6AI4V weldments.

In GTAWA and GTAWF, the microhardnes values taken on the fusion axis, the microhardnes increases from top to bottom. In the case of the LBW, the microhardnes, decreases from top to bottom of the fusion axis. The microhardness investigations were done along the fusion axis. Fig. 14.

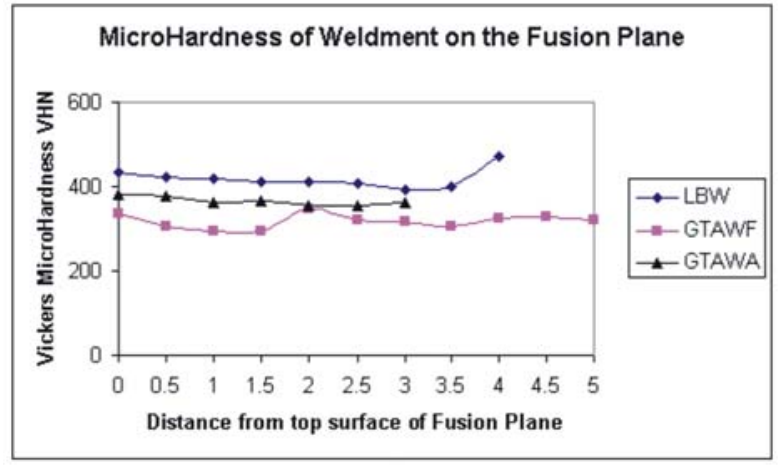

Fig. 14. Microhardness along Fusion Plane of GTAWF, GTAWA and LBW Ti6Al4V weldments.

Generally the fusion zone in the GTAW (autogenous) process has coarse columnar â grains, due to the high heat input and the thermal conditions prevailing during the solidification of the weldment.. In the fusion zone (FZ) of GTAWF more alpha prime (martensite) and some acicular alpha have formed. Fig. 15. 


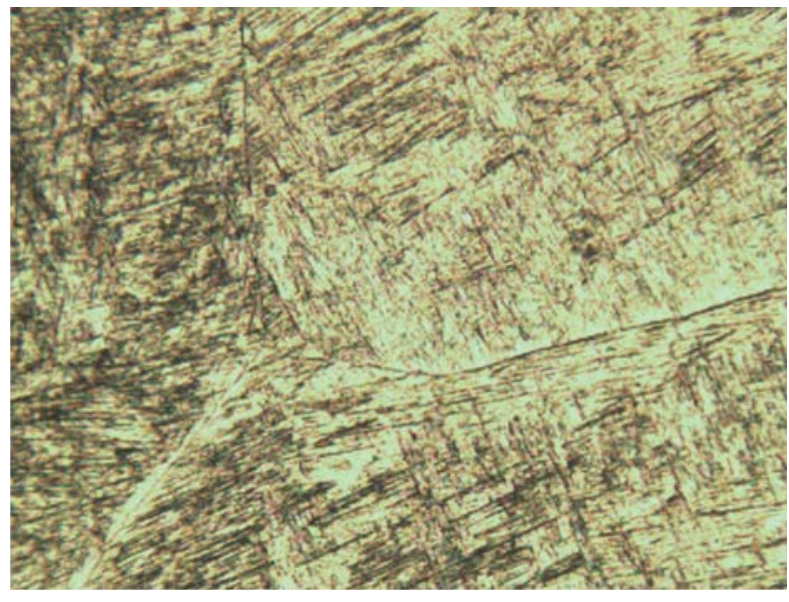

Fig. 15. Microstructure of GTAWF -FZ: 100X

The same structure has been formed in GTAWA, but the martensite formation is slightly less, due to the thermal conditions prevailing in the weldment. Fig. 16.

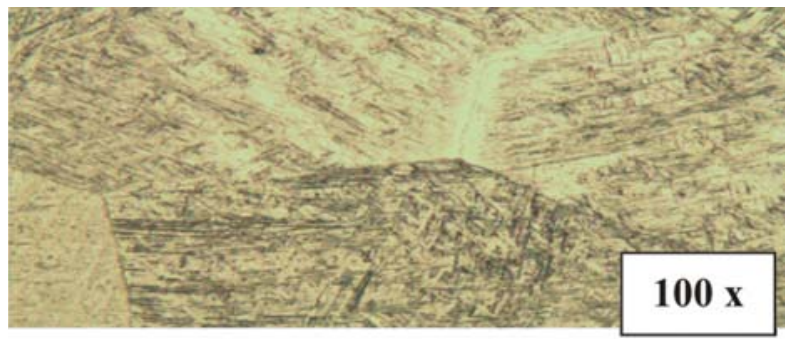

Fig.16. Microstructure of GTAWA-FZ: 100X

In GTAWF due to the high heat input more transformed beta grains (dark) are formed, primary alpha is present which would have been present before the transformation.

The microstructure, weld bead and the properties of the weldment are dependent on the mode of heat transfer, duration of exposure to the heat input and the heat gradient. In the GTAW, columnar grains are formed, whichyields inferior mechanical properties. In the heataffected zone (HAZ) of GTAWA and GTAWF, the primary alpha (light) is seen in a matrix of transformed beta.

Since the heat input is higher a broad heat affected zone is observed, causing the formation of more beta grains.

In the GTAWF the grains are well formed when compared to the GTAWA, because the filler wire has not been used in the autogenous process and led to lesser heat dissipation to the surrounding parent metal. Fig. 17, 18.

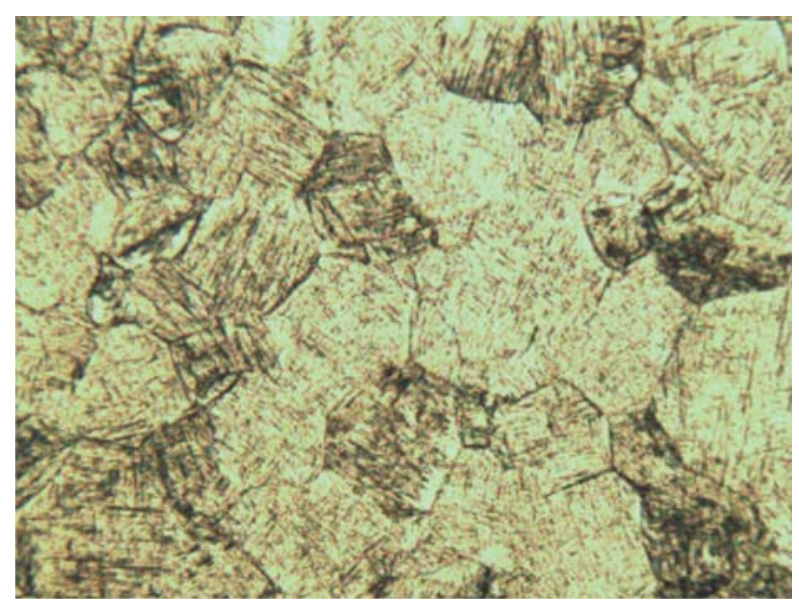

Fig. 17. Microstructure of GTAWF -HAZ: 100X

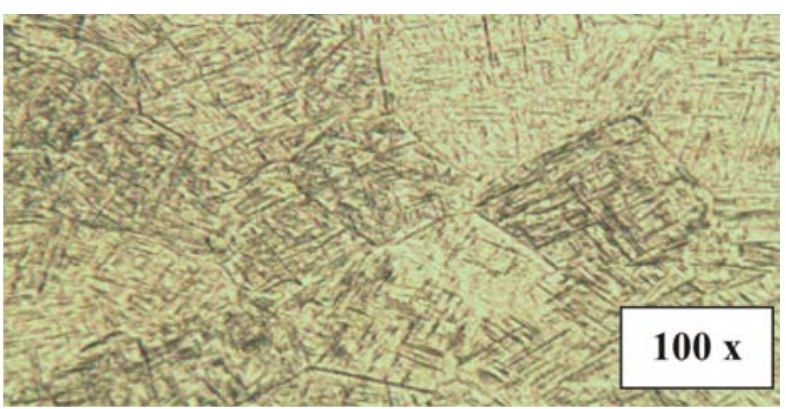

Fig. 18. Microstructure of GTAWA-HAZ: 100X

In the weld zone more transformed beta are present throughout the matrix with almost without any beta grains, which would have been present before the transformation. The primary alpha grains are seen as lighter areas. The dissipation of heat from the second weld pass (Fill up) has caused the adjacent layer of weld (Root), to cool slowly, leading to the formation of some alpha grains.

In the fusion zone (FZ) of LBW, the whole matrix has been converted into alpha prime (martensite), with the prior beta grain boundary. As the heat of the weld is more than the beta transus temperature, beta grains are formed and the grain boundaries are retained. The grains are larger due to high temperature and time of heating. Fig. 19.

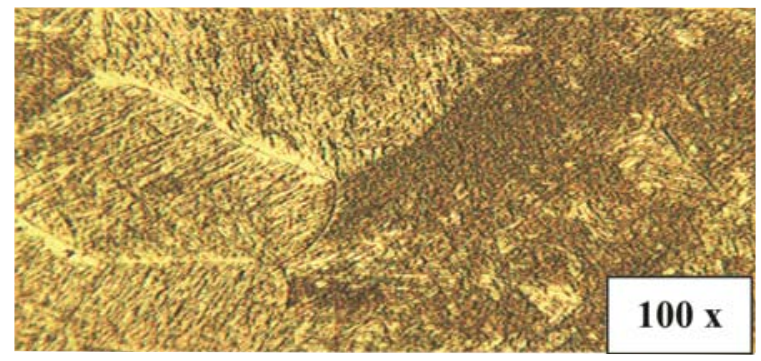

Fig. 19. Microstructure of LBW -FZ: 100X 
In the LBW the heat affected zone (HAZ) is very narrow, which is typical, due to the high energy delivered in a short period. Two regions are seen in the microphotograph, in the left side region shows the transformed beta grains formed due to heating near beta transus temperature and the rapid quenching. Since this region is adjacent to the weld zone, in the right side region of the heat-affected zone, partially transformed alpha prime (martensite) are observed with some primary alpha grains, which would have been present before the transformation. Fig. 20, 21.

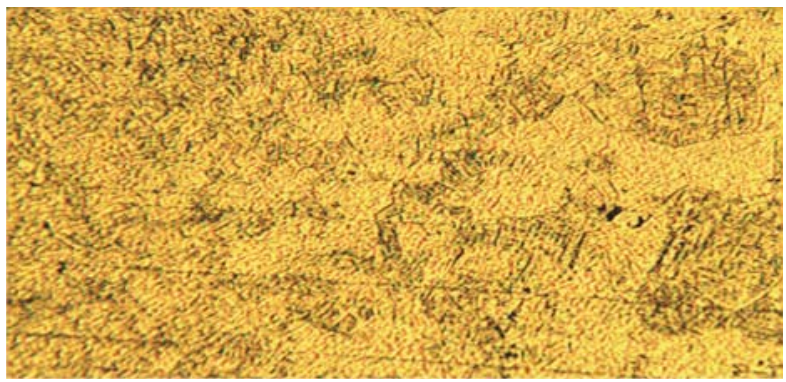

Fig. 20. Microstructure of LBW -PM/HAZ: 100X

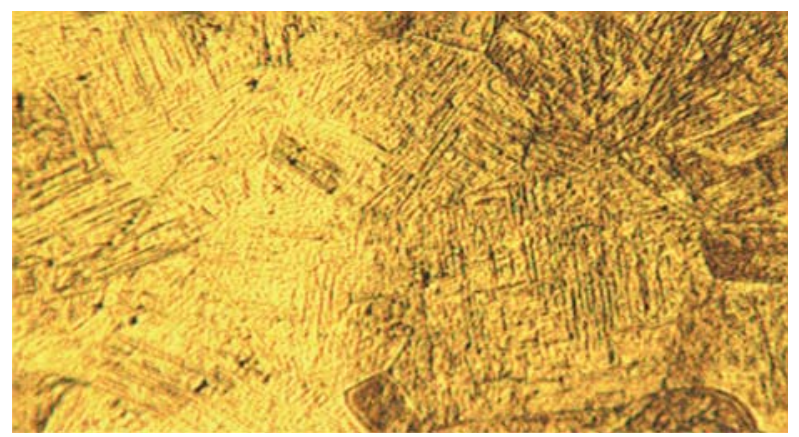

Fig. 21. Microstructure of LBW -HAZ/WM: 100X

Since the heat input in the laser beam welding is focused and localized and rapid heating followed by rapid cooli takes place. Here the $\beta$ transus temperature is maintained for shorter duration and immediately followed by rapid quenching by the surrounding shielding gas and the parent metal. This causes the raise in the microhardness through the formation of small grains of needle like á martensite microstructure in the heataffected zone, which is typical for weldments subjected to temperature above $\beta$ transus temperature. In the laser beam welding, the high-energy beam is highly focused, which does the welding within short time, by producing the weld through a series of over lapping nuggets and limits the wastage of heat by conduction to the adjacent parent metal. Thus the LBW produces weldments with small aspect ratio.

\section{CONCLUSION}

The $3 \mathrm{~mm}$ thick plates of Ti6Al4V fabricated by GTAWA, GTAWF and LBM were subjected to macrostructural, microstructure and Vickers hardness investigations. The macrostructural and microstructural investigations showed that the laser beam welding process produced a smaller aspect ratio when compared to GTAWA and GTAWF. The Vickers microhardness test showed a reduction in hardness in the fusion zone of weldments fabricated by GTAWA and GTAWF. This is attributed to the annealing effect caused by the multi pass welding process. Whereas the Vickers hardness value of the LBW was very high when compared to GTAWA and GTAWF, due to the rapid heating and quenching action. In the present investigation, the laser beam welding was found to produce better quality of weldments in Ti6Al4V plates.

\section{REFERENCES}

[1] ASM Metals Reference Book, American Society for Metals, Ohio, 2nd ed, 1983, pp. 100.

[2] Titanium for Offshore and Marine Applications - A Designers and Users Handbook, The Titanium Information Group, $2^{\text {nd }}$ ed, 1999.

[3] O.P.Khanna, "A Text Book of Material Science and Metallurgy" Dhanpat Rai Publishers, 2006, pp. $6.26-6.28$.

[4] R.R.Wang and G.E.Welsch, "Joining Titanium Materials with Tungsten Inert Gas Welding, Laser Welding and Infrared Brazing, The Journal of Prosthetic Dentistry, 1995, pp. 521-529.

[5] Wincok.C.Yung, B.Ralph, W.B.Lee and R.Fenn, "An Investigation into Welding Parameters Affecting the Tensile Properties of Titanium Weld, Journal of Materials Processing Technology, Vol. 63, 1997, pp. 759-764.

[6] Misra, M.S.Olson, D.L. and Edwards.G, "The Influence of Process Parameters and Specific Additions on Epitaxial Growth in Multiple Pass Ti6Al4V Welds", Grain Refinement in Castings and Welds, editors. G.J.Abbaschian and S.A.David, TMS/AIME, 1982, pp. 259.

[7] T.Mohandas, G.Madhusudan Reddy, "Effect of Frequency of Pulsing in Gas Tungsten Arc Welding on the Microstructure and Mechanical Properties of Titanium Alloy Welds: A Technical Note, Journal of Materials Science Letters, Vol. 15, 1996, pp. 626-628. 
[8] M.Balasubramanian, V.Jayabalan and V.Balasubramanian, "Effect of Microstructure on Impact Toughness of Pulsed Current GTA Werlded a- $\beta$ Titanium Alloy", Materials Letters, 2007.

[9] Liu Liming, Du Xin, Zhu Meili and Chen Guoqing, "Research on the microstructure and properties of weld repairs in TA15 titanium alloy," Materials Science and Engineering, Vol. A 445-446, 2007, pp. 691-696

[10] Larry Jeffus, "Welding - Principles and applications" Thomson - Delmar Learning, 5th ed, 2004, pp. 600-622.

[11] Sung H.Whang, "Review: Rapidly solidified Titanium alloys for high temperature applications", Journal of materials science, vol.21, 1986, pp. 2224-2238.

[12] Yanhong Wei, H.K.D.H.Bhadeshia and T. Sourmail, "Mechanical property prediction of commercially pure titanium welds with artificial neural network", Journal Of Materials Science Technology, Vol.21, No.3, 2005, Pp. 403-407.

[13] A.Zarei-Hanzaki, Z.Keshavarz and S.Yue, "The microstructural variations in Ti6Al4V during continuous cooling compression testing, Canadian Metallurgical Quaterly, Vol. 39, No.4, 2000, Pp. 513-520.

[14] M.Ya Brun and L.A.Bykova, "Effect of cooling regimes in heat treatment on the mechanical properties of titanium alloy VT3-1", All-Union institute of light alloys, No.12, 1985, Phleum Publishing Corporation, pp. 920-922.

[15] D.D.Harwig, C.Fountain, W.Ittiwattana and H.Castner," Oxygen equivalent effects on the mechanical properties of Titanium Welds", Welding research supplement, AWS, 2000, pp. 305s-315s.

[16] Ibrahim Ucok, Lawrence, S.Kramer, Mehmet N.Gungor, Philip Wolfe, HaoDong, Wm.Troy Track, "Effect of Wqelding on Microstructure and Tensile Propeerties of Flow formed Ti6Al4V Tube", Materials Science and Engineering, A410411, 2005, pp. 160-164.

[17] S.Sundaresan, G.D.Janakiram, G. Madsudhan Reddy, "Microstructural Refinement of Weld Fusion Zones in $\alpha-\beta$ Titanium Alloys Using Pulsed Current Welding, Material Science and Engineering, A262, 1999, pp. 88-100.
[18] Dr.Sun Zheng, Pan Dayou, Zhang Weihong, Tan Yang Kuang, "Correlation Between Processing Parameters and Microstructure in TIG, Plasma and Laser Welded Ti6Al4V Alloy, SIM Tech Technical Report, Singapore Institute of Manufacturing Technology, 2001, pp. 1-10.

[19] S.Mishra and T.Debroy, "Measurements and Monte Carlo Simulation of grain growth in the heataffected zone of Ti-6Al-4V welds," Acta Materialia, Vol. 52, 2004, pp. 1183-1192.

[20] F.Karimzadeh, A.Ebnonnasir and A.Foroughi, "Artificial neural network modeling for evaluating of epitaxial growth of Ti6Aal4V weldment," Materials Science and Engineering, Vol.A432, 2006, pp. 184-190.

[21] E.A.Metzbower, "Laser Beam Welding of Titanium, USA, pp. 311-318.

[22] F.Caiazzo, F.Curcio, G.Daurelio and F.Memola Capece Minutolo, "Ti6Al4V sheets lap and butt joints carried out by $\mathrm{CO} 2$ laser: mechanical and morphological characterization," Journal of Materials Processing Technology, Vol. 149, 2004, pp. 546-552.

[23] Larry Jeffus, "Welding - Principles and applications" Thomson - Delmar Learning, 5th ed, 2004, pp. 76.

[24] Akira Matsunawa, Naokiseto, Masami Mizutani and Seiji Katayama, "Liquid Motion in Key hole Laser Welding", Section G - ICALEO, 1998, pp. 151-159.

[25] John Dowden and Phiroze Kapadia, "Point and Line Sources: Models of Power Absorption in the theory of Welding", Section G - ICALEO, 1998, pp. 161-170.

[26] UNITEK MIYACHI Corporation - Nd: YAG Laser Welding Guide, 2003, pp. 1-18

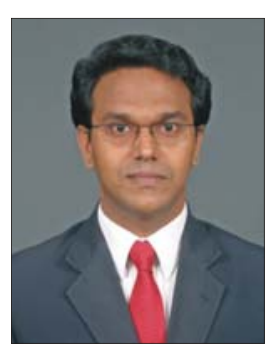

Mr. V. K. Bupesh Raja is a PostGraduate in Computer Aided Design from University of Madras and is a faculty at the Department of Mechanical and Production Engineering, Sathyabama University, Chennai. His field of research is "Welding of Ti6Al4V alloy". 